\title{
Low dynamic muscle strength and its associations with fatigue, functional performance, and quality of life in premenopausal patients with systemic lupus erythematosus and low disease activity: a case-control study
}

Sandor Balsamo ${ }^{1,2,3^{*}}$, Licia Maria Henrique da Mota ${ }^{1,2}$, Jozélio Freire de Carvalho ${ }^{4}$, Dahan da Cunha Nascimento ${ }^{3,5}$, Ramires Alsamir Tibana ${ }^{3,5}$, Frederico Santos de Santana ${ }^{1,2,3}$, Ricardo Lima Moreno ${ }^{6}$, Bruno Gualano ${ }^{7,8}$ and Leopoldo dos Santos-Neto ${ }^{1,2}$

\begin{abstract}
Background: The purpose of the present study was to compare dynamic muscle strength, functional performance, fatigue, and quality of life in premenopausal systemic lupus erythematosus (SLE) patients with low disease activity versus matched-healthy controls and to determine the association of dynamic muscle strength with fatigue, functional performance, and quality of life in SLE patients.

Methods: We evaluated premenopausal (18-45 years) SLE patients with low disease activity (Systemic lupus erythematosus disease activity index [SLEDAI]: mean $1.5 \pm 1.2)$. The control $(n=25)$ and patient $(n=25)$ groups were matched by age, physical characteristics, and the level of physical activities in daily life (International Physical Activity Questionnaire IPAQ). Both groups had not participated in regular exercise programs for at least six months prior to the study. Dynamic muscle strength was assessed by one-repetition maximum (1-RM) tests. Functional performance was assessed by the Timed Up and Go (TUG), in 30-s test a chair stand and arm curl using a 2-kg dumbbell and balance test, handgrip strength and a sit-and-reach flexibility test. Quality of life (SF-36) and fatigue were also measured.
\end{abstract}

Results: The SLE patients showed significantly lower dynamic muscle strength in all exercises (leg press 25.63\%, leg extension $11.19 \%$, leg curl $15.71 \%$, chest press 18.33\%, lat pulldown 13.56\%, 1-RM total load $18.12 \%, P<0.001-0.02$ ) compared to the controls. The SLE patients also had lower functional performance, greater fatigue and poorer quality of life. In addition, fatigue, SF-36 and functional performance accounted for $52 \%$ of the variance in dynamic muscle strength in the SLE patients.

Conclusions: Premenopausal SLE patients with low disease activity showed lower dynamic muscle strength, along with increased fatigue, reduced functional performance, and poorer quality of life when compared to matched controls.

Keywords: Dynamic muscle strength, Fatigue, Quality of life, Systemic lupus erythematosus, Functional performance

\footnotetext{
* Correspondence: sandorbalsamo@gmail.com

'Graduate Program in Medical Sciences, School of Medicine, Universidade de Brasília (UnB), Brasília, Brazil

${ }^{2}$ Rheumatology Service, Hospital Universitário de Brasília (HUB) UnB, Brasília,

Brazil

Full list of author information is available at the end of the article
} 


\section{Background}

It has been speculated that fatigue, a symptom frequently observed in approximately $80 \%$ of SLE patients [1], may contribute to a reduction in physical fitness (i.e., muscle weakness and low cardiovascular capacity), which, in turn, leads to an impairment in the performance of activities of daily living and consequently, in the overall quality of life [2].

Most studies examining the relationship between physical fitness and overall health in SLE patients have only addressed cardiovascular fitness [2]. However, decrements in muscle strength have also been strongly associated with a greater number of cardiovascular events $[3,4]$ and early mortality $[5,6]$ in several populations. Currently, the association between dynamic muscle strength, fatigue, functional performance, and quality of life in SLE patients remains unknown.

Previous studies have demonstrated that SLE patients have decreased isometric muscle strength when compared to healthy controls $[7,8]$. These studies evaluated muscle strength through isometric tests. Dynamic strength tests may be more informative than static tests for physical function evaluation because daily living functioning primarily encompasses dynamic rather than isometric contractions $[7,8]$. These previous studies also did not control for important confounding factors that affect physical performance, such as obesity [3], fibromyalgia $[9,10]$, perimenopause [11], smoking [12], using beta-blockers [13] and statins [14], activities of daily living and physical activity level [15], and socioeconomic status [7]. In the present study, we did correct for these confounding factors; therefore, their influence on the dependent variables may be considered minimal.

Thus, the objective of this study was twofold: 1) to compare dynamic muscle strength, functional performance, fatigue, and quality of life in premenopausal SLE patients with low disease activity versus matched-healthy controls and 2) to determine the association between dynamic muscle strength and fatigue, functional performance, and quality of life in these patients. We hypothesised that premenopausal SLE patients withp low disease activity would present reduced dynamic muscle strength when compared with their healthy peers. Furthermore, we hypothesised that low dynamic muscle strength would be associated with fatigue, poor functional performance, and impaired quality of life in SLE patients.

\section{Methods}

\section{Study design and patients}

The study was conducted between January 2009 and January 2011. A single examiner analysed the medical records and conducted structured interviews with 240 patients who were being followed in the outpatient Clinic of Rheumatology at the Brasilia University Hospital (HUB, Brasilia/Brazil). The interviews included socioeconomic status (e.g., education, employment, and income). Disease activity was assessed by the Systemic Lupus Erythematosus Disease Activity Index (SLEDAI) [16]. The control group was recruited through email, leaflets, and posters. Healthy women were primarily matched by physical activity levels, age and physical characteristics (i.e., body weight and body fat). The participants provided signed informed consent. The study was approved by the local ethics committee and was in accordance with the Helsinki Declaration of 1975, as revised in 1983.

\section{Inclusion criteria}

All participants were premenopausal women. The SLE patients met the American College of Rheumatology (ACR) criteria [16], with stable disease (i.e., no flare-ups or changes in medication for at least 3 months before entering the study) [17]. Additionally, all participants had not engaged in regular exercise programs for at least six months prior to the study [10].

\section{Exclusion criteria}

The following exclusion criteria were applied: SLEDAI > 5 ( $\mathrm{n}=19)$, serum creatinine $\geq 265 \mathrm{mmol} / \mathrm{l}$, myositis, haematocrit $\leq 30 \%$, nephritis and/or leukopenia $(n=13)$, history of myocardial infarction, cardiomyopathy, hypertension and/or the use of beta-blockers $(\mathrm{n}=18)$, type 2 diabetes mellitus $(\mathrm{n}=6)$, neurological diseases $(\mathrm{n}=4)$, hypothyroidism $(n=5)$, fibromyalgia $(n=23)$, osteoporosis $(\mathrm{n}=6)$, rheumatoid arthritis $(\mathrm{n}=3)$, Sjögren's syndrome $(\mathrm{n}=2)$, cancer $(\mathrm{n}=1)$, age $<18$ years $(\mathrm{n}=2)$ and $>$ 45 years $(n=39)$, residence located far (other state) from the research centre $(n=40)$, body mass index $(B M I)<18$ $\mathrm{kg} / \mathrm{m}^{2}(\mathrm{n}=1)$ and $>30 \mathrm{~kg} / \mathrm{m}^{2}(\mathrm{n}=8)$, smoking $(\mathrm{n}=10)$, pregnancy $(n=1)$, and engaged in regular exercise $(n=14)$.

\section{Methods}

The participants who met the inclusion criteria visited the laboratory on three different occasions in 48 to 72 hour intervals at the same time $(2-4 \mathrm{pm})$. Two days prior to the tests, the participants were recommended to avoid intensive exercise, caffeine or alcohol intake. The evaluations were not performed during the menstrual period. On the first day, fatigue symptoms, quality of life, and physical activity level were assessed $[15,18,19]$. Additionally, anthropometric measurements and functional performance tests were performed. The patients were also familiarised with the one-repetition maximum strength tests (1-RM). On the second and third days, the $1-R M$ test and re-test were performed, respectively.

\section{Anthropometric measurements}

A single examiner evaluated height, weight, and BMI. Body fat was estimated using the skinfold measurement, as previously described [20]. 
Fatigue symptoms, quality of life, and physical activity level All questionnaires were administered prior to the physical tests. The following fatigue scales were used: Fatigue Severity Scale (FSS) [1], which consists of a 9-question questionnaire with a score ranging from 1 to 7 . Quality of life was assessed using the Short-Form Health Survey 36 (SF-36) [19], which consists of 36 items grouped into eight sub-domains (i.e., physical functioning, rolephysical functioning, bodily pain, general health, vitality, social functioning, role-emotional functioning, and mental health). The SF-36 score ranges from 0 to 100 , with a higher score indicating better health-related quality of life. The level of physical activities of daily living was evaluated using the short version of the International Physical Activity Questionnaire (s-IPAQ) [18], which consists of questions regarding the frequency (i.e., days per week) and duration (i.e., minutes per day) of occupational and recreational activities of daily living and structured exercise programs according to the physical activity level. The subjects were classified into three categories: active, irregularly active, and inactive.

\section{Functional performance tests}

Physical function was assessed through the following battery of tests. The 30-s chair stand test evaluated the number of times that a subject was able to stand from a standard chair and sit down again in 30 seconds [21]. The 30-s arm curl test assessed upper-body muscle function by the number of arm curl repetitions performed with 2-kg dumbbell for 30 seconds [21]. The handgrip strength test (Takei Kiki Kogyo Co., Ltd., Japan) evaluated the maximal isometric strength of the dominant hand using a calibrated dynamometer. The volunteers stand erect holding the dynamometer parallel to the side, with the dial facing away from the body. Each participant performed the test twice, with a 1-minute rest period between the measurements. The best value was chosen for the analysis. The grip position of the TKK dynamometer was adjusted to the individual's hand size [22]. The Timed Up and Go (TUG) test assessed the time that a subject required to rise from a standard arm chair, walk 3 meters away, turn, return, and sit down again [23]. The one foot balance test with eyes closed assessed balance by having subject stand on one foot with eyes closed for up to 30 seconds [24]. The sit and reach test evaluated flexibility using the modified chair sit-and-reach test, as previously described [25].

\section{Dynamic muscle strength}

The 1-RM test was used to determine the dynamic muscle strength of the upper- and lower-limbs [26] using conventional weight machines (Johnson Health Technologies, Taiwan) [5,27-29]. Prior to the 1-RM test, two light warm-up sets were performed in two-minute intervals. Then, the participants were given up to five attempts to achieve the 1-RM load (i.e., the maximum weight that could be lifted once using proper technique), with a five-minute interval between the attempts. The 1RM tests were conducted for leg press, chest press, leg extension, lat pulldown, and leg curl exercises. The strength tests were performed on two different days and were separated by a 48-72 minute period, which allowed the calculation of the test-retest reliability (i.e., intraclass coefficient [ICC]) for both groups [28].

Sample size calculation was cited in a previous study [30] and assumed an effect size of 0.97 between groups; thus, a minimum sample of 25 volunteers for each group was required to provide $90 \%$ power ( $5 \%$ significance). The non-paired Student's T-test or Mann-Whitney Utest was used to compare the groups. Physical activity levels and socioeconomic status data were analysed by Pearson's chi-squared test.

The forward stepwise linear regression model was used to investigate the relationship between muscle strength (as the dependent variable) versus functional performance (i.e., 30-s chair stand test and handgrip tests), fatigue (i.e., FSS score), and quality of life (physical functioning subscale from SF-36) for the SLE patients. The regression model was applied as the 1RM-total (muscle strength: sum of total load lifted in the 1-RM tests [i.e., leg press + leg extension + leg curl + chest press + lat pulldown]), according to Ruiz et al. [5]. Normally distributed data are expressed as the mean \pm SD, and non-normally distributed data are expressed as median and interquartile range. The significance level was set at $5 \%$. The analyses were performed using the software SAS for Windows 9.2 (SAS Institute Inc., Cary, NC, USA).

\section{Results \\ Patients}

Twenty-five premenopausal SLE patients with a low disease activity (SLEDAI $=1.5 \pm 1.2$, range $=0-5,9$ of 25 patients) and a disease duration of $5.3 \pm 4.6$ years (range $=$ 1-20 years) participated in this study. The patients were taking corticosteroids $(21 / 25$ [84\%], dose $=6.07 \pm 2.1 \mathrm{mg}$ / day, range $=5-20 \mathrm{mg} /$ day), azathioprine ( 8 of 25 patients [32\%], dose $=87.50 \pm 46.8 \mathrm{mg} /$ day, range $50-200 \mathrm{mg} /$ day $)$, chloroquine diphosphate (17/25 [68\%], dose $=205.88 \pm$ $66.4 \mathrm{mg} /$ day), and hydroxychloroquine ( 2 of 25 patients [8\%], dose $=400 \pm 0.0 \mathrm{mg} /$ day). The primary characteristics of the SLE patients and the matched healthy controls are shown in Table 1.

\section{Socioeconomic status}

The SLE patients had lower educational level than the controls, $P<0.05)$. The groups did not differ regarding other socioeconomic status variables $(P>0.05)$ (Table 2$)$. 
Table 1 Main characteristics of SLE patients versus matched-healthy controls

\begin{tabular}{|c|c|c|c|c|}
\hline Variable & $\begin{array}{c}\text { SLE } \\
(n=25)\end{array}$ & $\begin{array}{l}\text { CONTROLS } \\
(n=25)\end{array}$ & $\begin{array}{l}\text { Difference between means } \\
\qquad(95 \% \mathrm{Cl})^{\#}\end{array}$ & $P$-value \\
\hline Age, years, median (IQR)† & $29.9(6.8)$ & $29.2(8.1)$ & & 0.7671 \\
\hline Body mass, kg & $57.7 \pm 6.7$ & $58.3 \pm 8.2$ & $0.69(-3.6,4.9)$ & 0.7462 \\
\hline Height, cm & $158.1 \pm 0.1$ & $158.3 \pm 0.9$ & $-0.01(-0.1,0.1)$ & 0.6573 \\
\hline Lean body mass, kg & $38.1 \pm 4.8$ & $38.5 \pm 3.8$ & $0.5(-2.1,2.9)$ & 0.6966 \\
\hline BMl, kg/height ${ }^{2}$ & $23.1 \pm 2.9$ & $23.5 \pm 3.3$ & $0.5(-13,2.2)$ & 0.5998 \\
\hline Body fat, $\%$ & $33.5 \pm 9.2$ & $33.2 \pm 8.6$ & $-0.3(-5.4,4.7)$ & 0.8997 \\
\hline Sum of skinfolds, mm & $79.8 \pm 19.4$ & $79.6 \pm 18.4$ & $-0.1(-10.9,10.6)$ & 0.9769 \\
\hline Thigh skinfold, mm & $23.1 \pm 5.6$ & $22.3 \pm 6.4$ & $-0.8(-4.2,2.6)$ & 0.6351 \\
\hline Right thigh circumference, $\mathrm{cm}$ & $55.2 \pm 4.2$ & $56.2 \pm 3.6$ & $1.1(-1.2,3.3)$ & 0.3404 \\
\hline Systolic blood pressure, $\mathrm{mmHg}$ & $108.0 \pm 10.2$ & $106 \pm 8.6$ & $-2.3(-7.7,3.1)$ & 0.3818 \\
\hline Diastolic blood pressure, mmHg, median (IQR) $\dagger$ & $68.0(11.4)$ & $69.0(9.8)$ & & 0.7410 \\
\hline Heart rate, bpm & $80.0 \pm 10.3$ & $81.0 \pm 14.9$ & $1.2(-6.1,8.5)$ & 0.7432 \\
\hline
\end{tabular}

* Values are expressed as the mean \pm SD unless otherwise stated. $\dagger$ These variables are not normally distributed and therefore, are expressed as median. \# Calculated only when Student's t-test was used. SLE systemic lupus erythematosus, $\mathrm{Cl}$ confidence interval, IQR interquartile range, $B M I$ body mass index, $m m H g$ millimetres of Mercury, BPM beats per minute.

\section{s-IPAQ}

None of the participants had engaged in regular exercise programs for at least six months prior to the study. The level of physical activities of daily living was similar between the groups $(P=0.12)$. In the SLE group, 17 of 25 $(68 \%)$ patients were active, 3 of 25 (12\%) were irregularly active, and 5 of 25 (20\%) were inactive. In the control group, 23 of 25 (92\%) subjects were active, 1 of 25 (4\%) was irregularly active, and 1 of 25 (4\%) was inactive.

\section{Fatigue symptom and quality of life}

When compared with the controls, the SLE patients had significantly higher FSS score $(P<0.01)$. The SLE patients also had poorer quality of life parameters when compared with the controls, (all $P<0.05$ ), except for vitality and bodily pain domains (both $P>0.05$ ) (Table 3 ).

\section{Functional performance}

When compared with the controls, the SLE patients had a significantly lower functional performance in general (handgrip test $=-10.35 \%$, TUG test $=-5.94 \%$, 30-s chair timed-stand test $=-18.60 \%$, 30-s arm curl test $=$ - 16.58\%, all $P<0.05$ ), except for balance and flexibility (both $P>0.05$ ) (Table 3 ).

\section{Muscle strength (1-RM)}

The ICC for the 1-RM test was 0.98 (CI 0.60, 0.99) and 0.99 (CI 0.86, 0.98) for the SLE and control groups, respectively. The SLE patients had a significantly lower $1-\mathrm{RM}$ than the controls in all exercises (1-RM = $-25.63 \%$, leg extension $=-11.19 \%$, leg curl $=-15.71 \%$, chest press $=-18.33 \%$, lat pulldown $=-13.56 \%, 1-\mathrm{RM}$ [total load] $=-18.12 \%, 1-\mathrm{RM} /$ relative $[$ total load $/$ body weight $=-17 \%$, all $P<0.05]$ ) (Table 4$)$.

\section{Linear regression model}

The final model for dynamic muscle strength, which included the functional performance tests (handgrip and timed chair stands), SF-36 (physical role functioning and emotional role functioning scores), and FSS scores, accounted for $52 \%$ of the variance in dynamic muscle strength $(\mathrm{F}=5.62, \mathrm{P}=0.02$, VIF $<10$, Table 5). Unexpectedly, physical role functioning was

Table 2 Socioeconomic characteristics of the SLE patients and healthy controls

\begin{tabular}{|c|c|c|c|c|c|}
\hline \multirow[t]{3}{*}{ Variable } & \multicolumn{4}{|c|}{ Group } & \multirow{3}{*}{$P$-value } \\
\hline & \multicolumn{2}{|c|}{ SLE } & \multicolumn{2}{|c|}{ CONTROLS } & \\
\hline & $\mathbf{N}$ & $\%$ & $\mathbf{N}$ & $\%$ & \\
\hline \multicolumn{6}{|l|}{ Educational level } \\
\hline Literacy, 0 to 4 years & 3 & 12 & 0 & 0 & 0.0003 \\
\hline Primary, 5 to 8 years & 8 & 32 & 0 & 0 & \\
\hline Secondary, 9 to 12 years & 9 & 36 & 23 & 92 & \\
\hline University, 12 years > & 5 & 20 & 2 & 8 & \\
\hline \multicolumn{6}{|l|}{ Employment } \\
\hline Paid & 14 & 56 & 19 & 76 & 0.0702 \\
\hline Unemployed & 11 & 44 & 6 & 24 & \\
\hline \multicolumn{6}{|l|}{ Incomet } \\
\hline No income & 10 & 40 & 6 & 24 & 0.5345 \\
\hline Up to 1 minimum salary & 6 & 24 & 8 & 32 & \\
\hline From 1 to 2 minimum salaries & 6 & 24 & 8 & 32 & \\
\hline Over 2 minimum salaries & 3 & 12 & 3 & 12 & \\
\hline
\end{tabular}

† Brazilian minimum salary equivalent to US\$280.00 in 2009 (R\$ 465.00). 
Table 3 Functional capacity, fatigue scores and quality of life in the SLE patients and controls*

\begin{tabular}{|c|c|c|c|c|}
\hline Variable & $\begin{array}{c}\text { SLE } \\
(n=25)\end{array}$ & $\begin{array}{l}\text { CONTROLS } \\
(\mathrm{n}=25)\end{array}$ & $\begin{array}{l}\text { Difference between means } \\
\qquad(95 \% \mathrm{Cl})^{\#}\end{array}$ & $P$-value \\
\hline \multicolumn{5}{|l|}{ Functional performance } \\
\hline Handgrip strength, kg & $24.2 \pm 4.9$ & $27.1 \pm 4.7$ & $2.8(0.1 ; 5.5)$ & 0.0464 \\
\hline 30-s chair stand test, repetitions & $19.6 \pm 5.6$ & $24.1 \pm 3.7$ & $4.5(1.7 ; 7.2)$ & 0.0018 \\
\hline 30-s arm curl test, repetitions & $20.5 \pm 3.3$ & $24.6 \pm 3.6$ & $4.1(2.1 ; 6.1)$ & 0.0001 \\
\hline Timed Up and Go, s & $5.3 \pm 0.4$ & $5.0 \pm 0.6$ & $-0.3(-0.6 ;-0.0)$ & 0.0495 \\
\hline Flexibility sit and reach, $\mathrm{cm}$ & $24.0 \pm 9.5$ & $29.0 \pm 9.4$ & $5.0(-0.40 ; 10.4)$ & 0.0680 \\
\hline 30-s balance, s & $17.6(9.8)$ & $17.0(9.1)$ & - & 0.7848 \\
\hline \multicolumn{5}{|l|}{ Fatigue symptom } \\
\hline FSS, median (IQR) $\dagger$ & $3.5(1.2)$ & $2.5(0.9)$ & - & 0.0043 \\
\hline \multicolumn{5}{|l|}{ Quality of life, SF-36 } \\
\hline Physical functioning, median (IQR)† & $61.6(24.4)$ & $81.2(14.5)$ & - & 0.0029 \\
\hline Role-physical functioning, median (IQR)† & $53.0(41.03)$ & $78.0(25.3)$ & - & 0.0375 \\
\hline Bodily pain, median (IQR)† & $64.4(25.7)$ & $72.9(22.0)$ & - & 0.2752 \\
\hline General health & $51.1 \pm 17.8$ & $67.4 \pm 16.3$ & $16.3(6.6 ; 26.0)$ & 0.0014 \\
\hline Vitality, median (IQR)† & $54.8(11.5)$ & $55.2(10.3)$ & - & 0.9686 \\
\hline Social functioning, median (IQR)† & $68.4(24.0)$ & $83.8(18.3)$ & - & 0.0266 \\
\hline Role-emotional functioning & $41.1(39.9)$ & $73.2(36.1)$ & - & 0.0073 \\
\hline Mental health, median (IQR)† & $50.0(13.2)$ & $58.5(10.6)$ & $8.5(1.7 ; 15.3)$ & 0.0150 \\
\hline
\end{tabular}

* Values expressed as the mean \pm SD, unless otherwise stated. † These variables are not normally distributed and therefore are expressed as median. \# Calculated only when Student's t-test was used. SLE systemic lupus erythematosus, $C I$ confidence interval, FSS fatigue severity scale, IQR interquartile range.

inversely related to $1-\mathrm{RM}$ in the final model. However, physical role functioning seemed to be a weak independent factor in $1-\mathrm{RM}$ change $\left(\mathrm{R}^{2}=0.14\right.$; $=$ -0.38 ), therefore the role of this variable as a predictor in the final model must be interpreted with caution. The errors in the model were independently distributed (Durbin-Watson $=2.19$ ), and multicollinearity was not detected (VIF $=1.0)$.

\section{Adverse events}

No adverse events were recorded during the experimental period. Additionally, none of the patients reported joint pain at time of testing.

\section{Discussion}

The novel finding of this study is that premenopausal SLE patients with low disease activity show lower

Table 4 Dynamic muscle strength (1-RM) in SLE patients and controls*

\begin{tabular}{|c|c|c|c|c|}
\hline Variable (1-RM) & $\begin{array}{l}\text { SLE } \\
(\mathrm{n}=25)\end{array}$ & $\begin{array}{l}\text { CONTROLS } \\
(n=25)\end{array}$ & $\begin{array}{l}\text { Difference between means } \\
(95 \% \mathrm{Cl})^{\#}\end{array}$ & $P$-value \\
\hline Leg press, $\mathrm{kg}$ & $71.1 \pm 18.6$ & $95.6 \pm 19.7$ & $24.5(13.6 ; 35.5)$ & $<0.0001$ \\
\hline Leg extension, kg & $64.7 \pm 10.6$ & $72.9 \pm 13.9$ & $8.1(1.1 ; 15.2)$ & 0.0242 \\
\hline Leg curl, kg & $30.2 \pm 5.2$ & $35.8 \pm 6.9$ & $5.6(2.1 ; 9.1)$ & 0.0022 \\
\hline Chest press, kg & $34.7 \pm 7.2$ & $43.1 \pm 7.9$ & $8.4(4.1 ; 12.7)$ & 0.0002 \\
\hline Lat pulldown, kg & $36.2 \pm 6.4$ & $41.8 \pm 5.8$ & $5.6(2.2 ; 9.1)$ & 0.0019 \\
\hline 1-RM-total, kg & $47.4 \pm 8.1$ & $57.8 \pm 8.7$ & $10.4(5.7 ; 15.0)$ & $<0.0001$ \\
\hline 1-RM-total, kg/kg of body weight & $0.8 \pm 0.1$ & $1.0 \pm 0.1$ & $0.2(0.1 ; 0.2)$ & $<0.0001$ \\
\hline
\end{tabular}

* These values are expressed as the mean SD unless otherwise stated. $\dagger$ These variables are not normally distributed and therefore, are expressed as median. \# Calculated only when Student's t-test was used. SLE = systemic lupus erythematosus; $\mathrm{Cl}=$ confidence interval of 95\%; 1-RM = 1-RM consists of performing a full range of motion with the greatest possible load; 1-RM -total = sum of total load lifted in the 1-RM tests (i.e., leg press, leg extension, leg curl, chest press, and lat pulldown); 1-RM-total, $\mathrm{kg} / \mathrm{kg}$ of body weight = median of the sum of the load of the 1-RM tests in leg press, leg extension, leg curl, chest press, and lat pulldown divided by body weight. 
Table 5 Association between dynamic muscle strength and functional performance tests, SF-36 subscale and fatigue score

\begin{tabular}{llllll}
\hline Dependent variable & Independent variable & $\hat{\boldsymbol{\beta}}$ & Standard error & $\mathbf{R}^{\mathbf{2}}$ & $\boldsymbol{P}_{\text {-value }}$ \\
\hline 1-RM-total, kg & Role-physical functioning (SF-36) & -0.38 & 0.09 & 0.14 & 0.001 \\
& Handgrip test & 2.09 & 0.61 & 0.22 & 0.0027 \\
& Role-emotional functioning (SF-36) & 0.23 & 0.08 & 0.0125 \\
& Timed chair-stand test & 1.61 & 0.53 & 0.42 & 0.0065 \\
& Fatigue (FSS) & -9.80 & 4.13 & 0.0218 \\
\hline
\end{tabular}

$\hat{\beta}=$ parameter estimate, $R^{2}=$ coefficient of determination; 1-RM = one repetition maximum is the largest possible load of a particular movement; 1-RM -total = sum of total load lifted in the 1-RM tests (i.e., leg press, leg extension, leg curl, chest press, and lat pulldown); SF-36 self-administered health questionnaire - Short Form Health Survey 36, FSS fatigue severity scale.

dynamic muscle strength (upper- and lower-limb) when compared with their healthy peers. Furthermore, we provided the evidence that lower dynamic muscle strength was associated with fatigue, low functional performance, and poor quality of life (namely, role-emotional functioning) in SLE patients.

Our results are in agreement with those by Tench et al. [7] and Stockton et al. [8], who demonstrated that SLE patients have lower isometric muscle strength when compared with healthy controls. However, the aforementioned studies evaluated muscle strength using isometric tests. In this regard, one may argue that dynamic strength tests may be more informative than static tests in terms of physical function evaluation because daily living functioning primarily encompasses dynamic rather than isometric contractions [7]. In fact, the significant association between dynamic strength (i.e., 1-RM) and physical function assessments (i.e., chair timed-stands) observed in the current study further supports this notion.

Fatigue scores (as assessed by the FSS questionnaire) lower than 4.0 suggest that fatigue is not severe enough to limit participation in daily living physical activities. Conversely, FSS scores higher than 4.0 suggest that fatigue is perceived to adversely affect the ability to engage in physical and social activities [1]. In the current study, however, the SLE patients scored 3.5 on average (with 15 of 25 patients having FSS scores lower than 4). However, the patients experienced decreased physical function, low dynamic muscle strength capacity, and poor quality of life, suggesting that either "residual" fatigue or other factors (e.g., long-term medication or systemic inflammation) may have contributed to the poor health-related findings demonstrated in this study. Further studies must elucidate the role of fatigue on health-related parameters in SLE patients.

We observed that even with low fatigue and low disease activity scores, $20 \%$ (5 of 25) of the SLE patients showed handgrip strength between 17 and $20 \mathrm{~kg}$. Notably, these values are considered a marker of sarcopenia [23]. The handgrip strength test has been considered a clinical marker of mobility $[23,31]$ and lower limb muscle strength [23]. Moreover, a 5-kg increase in handgrip strength has been associated with a significantly reduced mortality risk
[6]. This fact, along with the fact that the handgrip strength test has been proven reliable in SLE patients [32], make this simple and inexpensive tool an emerging marker of clinical relevance. Further prospective studies should test its ability as a prognostic marker in SLE.

Our study must be interpreted in light of its strengths and limitations. Although a few studies have also demonstrated lower physical function in SLE patients [7,8], these studies did not control for important confounding factors that affect physical performance, such as obesity [3], fibromyalgia $[9,10]$, perimenopause [11], smoking [12], use of beta-blocker [13] and statins [14], activities of daily living, physical activity level [15], and socioeconomic-status [7]. In the present study, we did correct for these confounding factors; therefore, their influence on the muscle strength may be considered minimal.

However, this study is not without limitations. First, the cross-sectional nature of this study precluded us to establish cause-effect relationships between muscle strength and health-related parameters in SLE patients (e.g., role-emotional functioning from SF-36). Second, our homogeneous sample comprised premenopausal SLE patients with low disease activity and who were free of comorbidities and associated diseases. Therefore, one cannot extrapolate the present results to older or younger patients with more severe disease. Finally, our sample size was relatively low. Further studies should test the accuracy of our multivariate model in a larger patient cohort.

\section{Conclusions}

In conclusion, the current study provided novel evidence that lower- and upper-body dynamic muscle strength is reduced in premenopausal SLE patients with low disease activity when compared with their controls. Importantly, we also demonstrated that lower dynamic muscle strength is associated with fatigue, low functional performance, and poor quality of life in SLE patients.

\section{Competing interests}

This research received no specific grant from any funding agency in the public, commercial, or not-for-profit sectors. The authors declare no competing interest. 


\section{Author's contributions}

SB, LSN, DCN, RAT and FSS were responsible for concept and design, statistical expertise, data analysis and interpretation, helped write the manuscript. SB and LSN were responsible for data analysis and interpretation and helped write the manuscript, BC, JFC, RCM and LMHM were significant manuscript reviewers/ revisers and were responsible for data analysis and interpretation. SB, LSN and BC were significant manuscript reviewers/revisers and were responsible for data acquisition. BC, JFC, RCM and LMHM were a significant manuscript reviewer/reviser and were responsible for data acquisition, analysis and interpretation. All authors have read and approved the manuscript for publication.

\section{Acknowledgments}

The present study is part of the LUPUSFIT Study, which aims to explore the influence of physical fitness upon a variety of health-related parameters in Brazilian patients with SLE in association with the laboratory of Physical Fitness and Rheumatology of Brasília - LAR Brasília. We would like to thank Francisco Aires Correa Lima, Rodrigo Lima, Cezar Kozak, Regina A F Von Kircheheim, Ana Oliveira, Clarissa Ferreira, and Larissa Pessoa for screening the patients.

\section{Author details}

Graduate Program in Medical Sciences, School of Medicine, Universidade de Brasília (UnB), Brasília, Brazil. ${ }^{2}$ Rheumatology Service, Hospital Universitário de Brasília (HUB) UnB, Brasília, Brazil. ${ }^{3}$ Physical Education Department, Centro Universitário UNIEURO, Brasília, Brazil. ${ }^{4}$ Rheumatology Division, Clínica de Oncologia (CLION), Salvador, Brazil. ${ }^{5}$ Graduate Program on Physical Education, Catholic University of Brasilia, Brasilia, Brazil. ${ }^{6}$ School of Physical Education, UnB, Brasília, Brasilia, Brazil. ${ }^{7}$ School of Physical Education and Sports, University of Sao Paulo (USP), Sao Paulo, Brazil. ${ }^{8}$ School of Medicine, Rheumatology Division, USP, Sao Paulo, Brazil.

Received: 26 February 2013 Accepted: 21 August 2013 Published: 8 September 2013

\section{References}

1. Krupp LB, LaRocca NG, Muir J, Steinberg AD: A study of fatigue in systemic lupus erythematosus. J Rheumatol 1990, 17:1450-1452.

2. Balsamo S, Santos-Neto LD: Fatigue in systemic lupus erythematosus: an association with reduced physical fitness. Autoimmun Rev 2011, 10:514518

3. Wijndaele K, Duvigneaud N, Matton L, Duquet W, Thomis M, Beunen G, et al: Muscular strength, aerobic fitness, and metabolic syndrome risk in Flemish adults. Med Sci Sports Exerc 2007, 39:233-240.

4. Gale CR, Martyn CN, Cooper C, Sayer AA: Grip strength, body composition, and mortality. Int J Epidemiol 2007, 36:228-235.

5. Ruiz JR, Sui X, Lobelo F, Morrow JR Jr, Jackson AW, Sjostrom M, et al: Association between muscular strength and mortality in men: prospective cohort study. BMJ 2008, 337:a439.

6. Sasaki H, Kasagi F, Yamada M, Fujita S: Grip strength predicts cause-specific mortality in middle-aged and elderly persons. Am J Med 2007, 120:337-342.

7. Tench C, Bentley D, Vleck V, McCurdie I, White P, D'Cruz D: Aerobic fitness, fatigue, and physical disability in systemic lupus erythematosus. J Rheumatol 2002, 29:474-481.

8. Stockton KA, Kandiah DA, Paratz JD, Bennell KL: Fatigue, muscle strength and vitamin D status in women with systemic lupus erythematosus compared to healthy controls. Lupus 2011.

9. Aparicio VA, Ortega FB, Heredia JM, Carbonell-Baeza A, Sjostrom M, Delgado-Fernandez M: Handgrip strength test as a complementary tool in the assessment of fibromyalgia severity in women. Arch Phys Med Rehabil 2011, 92:83-88.

10. Valkeinen $\mathrm{H}$, Hakkinen A, Alen M, Hannonen P, Kukkonen-Harjula K, Hakkinen K: Physical fitness in postmenopausal women with fibromyalgia. Int J Sports Med 2008, 29:408-413.

11. Oliveira RJ, Bottaro M, Junior JT, Farinatti PT, Bezerra LA, Lima RM: Identification of sarcopenic obesity in postmenopausal women: a cutoff proposal. Braz J Med Biol Res 2011, 44:1171-1176.

12. Ostbye T, Taylor DH Jr, Krause KM, van Scoyoc L: The role of smoking and other modifiable lifestyle risk factors in maintaining and restoring lowe body mobility in middle-aged and older Americans: results from the HRS and AHEAD. Health and Retirement Study. Asset and Health Dynamics Among the Oldest Old. J Am Geriatr Soc 2002, 50:691-699.

13. Helfand M, Peterson K, Christensen V, Dana T, Thakurta S: Drug Class Review: Beta Adrenergic Blockers: Final Report Update 4 [Internet]; 2009. Available from: http://www.ncbi.nlm.nih.gov/books/NBK47172/.

14. Evangelista LS, Moser DK, Westlake C, Pike N, Ter-Galstanyan A, Dracup K: Correlates of fatigue in patients with heart failure. Prog Cardiovasc Nurs 2008, 23:12-17.

15. Keyser RE, Rus V, Cade WT, Kalappa N, Flores RH, Handwerger BS: Evidence for aerobic insufficiency in women with systemic Lupus erythematosus. Arthritis Rheum 2003, 49:16-22.

16. Bombardier C, Gladman DD, Urowitz MB, Caron D, Chang CH: Derivation of the SLEDAI. A disease activity index for lupus patients. The Committee on Prognosis Studies in SLE. Arthritis Rheum 1992, 35:630-640.

17. Cook RJ, Gladman DD, Pericak D, Urowitz MB: Prediction of short term mortality in systemic lupus erythematosus with time dependent measures of disease activity. J Rheumatol 2000, 27:1892-1895.

18. Craig CL, Marshall AL, Sjostrom M, Bauman AE, Booth ML, Ainsworth BE, et al: International physical activity questionnaire: 12-country reliability and validity. Med Sci Sports Exerc 2003, 35:1381-1395.

19. Stoll T, Gordon C, Seifert B, Richardson K, Malik J, Bacon PA, et al: Consistency and validity of patient administered assessment of quality of life by the MOS SF-36; its association with disease activity and damage in patients with systemic lupus erythematosus. J Rheumatol 1997, 24:1608-1614.

20. Jackson AS, Pollock ML, Ward A: Generalized equations for predicting body density of women. Med Sci Sports Exerc 1980, 12:175-181.

21. Rikli RE, Jones J: The senior fitness test. Defining functional fitness parameters. In Senior Fitness Test Manual. Edited by Rikli RE, Jones J. Champaign, IL: Human Kinetics; 2001:11-24.

22. Heyward $\mathrm{VH}$ : Assessing muscular fitness. In Advanced fitness assessment Edited by Heyward VH. Champaign, IL: Human Kinetics; 2010:129-154.

23. Cruz-Jentoft AJ, Baeyens JP, Bauer JM, Boirie Y, Cederholm T, Landi F, et al: Sarcopenia: European consensus on definition and diagnosis: Report of the European Working Group on Sarcopenia in Older People. Age Ageing 2010, 39:412-423.

24. Toulotte C, Thevenon A, Fabre C: Effects of training and detraining on the static and dynamic balance in elderly fallers and non-fallers: a pilot study. Disabil Rehabil 2006, 28:125-133.

25. Heyward VH: Assessing flexibility. In Advanced fitness assessment. Edited by Heyward VH. Champaign, IL: Human Kinetics; 2010:265-282.

26. Kraemer WJ, Ratamess NA, Fry A, French DN: Strength testing: development and evalution on methodology. In Physiological assessment of human fitness. Edited by Maud P, Foster C. Champaign, IL: Human Kinetics; 2006:119-150

27. Dourado VZ, Antunes LC, Tanni SE, de Paiva SA, Padovani CR, Godoy Relationship of upper-limb and thoracic muscle strength to 6-min walk distance in COPD patients. Chest 2006, 129:551-557.

28. Levinger I, Goodman C, Hare DL, Jerums G, Toia D, Selig S: The reliability of the 1RM strength test for untrained middle-aged individuals. J Sci Med Sport 2009, 12:310-316.

29. Villareal DT, Chode S, Parimi N, Sinacore DR, Hilton T, Armamento-Villareal R, et al: Weight loss, exercise, or both and physical function in obese older adults. N Engl J Med 2011, 364:1218-1229.

30. Balsamo S, Nascimento DD, Tibana RA, Santana FS, Mota LM, Santos-Neto $L L$ : The quality of life of patients with lupus erythematosus influences cardiovascular capacity in 6-minute walk test. Rev Bras Reumatol 2013, 53:81-87.

31. Xue QL, Walston JD, Fried LP, Beamer BA: Prediction of Risk of Falling, Physical Disability, and Frailty by Rate of Decline in Grip Strength: The Women's Health and Aging Study. Arch Intern Med 2011, 171:1119-1121.

32. Stockton KA, Wrigley TV, Mengersen KA, Kandiah DA, Paratz JD, Bennell KL: Test-retest reliability of hand-held dynamometry and functional tests in systemic lupus erythematosus. Lupus 2011, 20:144-150.

doi:10.1186/1471-2474-14-263

Cite this article as: Balsamo et al.: Low dynamic muscle strength and its associations with fatigue, functional performance, and quality of life in premenopausal patients with systemic lupus erythematosus and low disease activity: a case-control study. BMC Musculoskeletal Disorders $201314: 263$ 